Reprod. Nutr. Dévelop., 1980, 20 (3 A), 719-726.

\title{
Analysis of an Hertwig effect in the rainbow trout (Salmo gairdneri Richardson) after fertilization with $\gamma$-irradiated sperm
}

\author{
D. CHOURROUT, B. CHEVASSUS, Françoise HERIOUX
}

Laboratoire de Physiologie des Poissons, I.N.R.A.

78350 Jouy-en-josas, France

Summary. In this work, we tried to optimize $\gamma$-treatment of sperm to obtain large numbers of haploid gynogenetic embryos after fertilization.

The analysis of increasing doses showed a typical « Hertwig effect » in all cases, but we found wide between-male variations in the most efficient dose. This variability was reduced by mixing several irradiated samples collected from different males or given different efficient doses.

\section{Introduction.}

Since Hertwig's work on Rana fusca in 1911, gynogenesis, a type of parthenogenetic development triggered by a genetically inert spermatozoon, has been induced in many vertebrates (Rostand, 1934 ; Fankhauser, 1945) and more recently in several fish species by means of $X$ or $\gamma$ irradiated sperm (Romashov ef al., 1963 ; Golovinskaïa, 1968 ; Purdom, 1969). This treatment leads to haploid development with early abortion generally before or immediately after hatching time. Cold-shocking the eggs in the first minutes after fertilization prevents the extrusion of the second polar body in some zygotes and gives rise to diploid gynogenetic fry.

It would be especially advantageous to induce gynogenesis in commercial species as a direct way of producing monosexual populations (Stanley, 1976 ; Nagy ef al., 1978) and highly inbred lines (Nagy ef al., 1978). Several works on salmonids described the obtention of haploid development but failed to induce diploidization (Purdom, 1969 ; Lincoln ef al., 1974).

We tried in this first paper to optimize the $\gamma$-irradiation technique by determining the best dose, and by localizing and reducing the causes of residual variations.

\section{Material and methods.}

The sperm of one or several rainbow trout males was removed and distributed in equal volumes into $5 \mathrm{ml}$ tubes held on ice in the irradiation room ; $\gamma$-rays were delivered by $a^{60} \mathrm{Co}$ « Pagure » source (CEN, Saclay) with a maximum of $900 \mathrm{krad} / \mathrm{hr}$. 
We analysed doses between 7.5 and $375 \mathrm{krad}$; the duration of the treatment varied from 15 to $60 \mathrm{~min}$. Recently ovulated eggs (1000 to $3000 /$ female rainbow trout) were collected, and kept at $4{ }^{\circ} \mathrm{C}$ until fertilization. They were drained and distributed in equal batches of 200 each. Dry fertilization was carried out as follows : 0.2 to $1 \mathrm{cc}$ of sperm was placed over the eggs then diluted with 10 to $20 \mathrm{cc}$ of a sperm diluent (saline buffered solution $\mathrm{pH}$ 9) (Billard, 1974) ; each batch was let stand for $15 \mathrm{~min}$ and then introduced into a thermoregulated $\left(10^{\circ} \mathrm{C}\right)$ recirculating incubation system. At that temperature, embryonic development comprises three stages (Vernier, 1969) : (i) segmentation (Day 0 to Day 4), (ii) gastrulation (Day 5 to Day 10), and (iii) tailbud (Day 11 to Day 35). The eggs can be handled from Day 20 which corresponds to the beginning of the eyed-stage, characterized by the advent of melanine in the optic vesicles. To sort the batches, we first separated the dead ( $W=$ white) from the live eggs. Those with an embryo $(E)$ could be easily distinguished at the eyed-stage from the unfertilized eggs ( $C=$ clear) (at an earlier stage, we had used Stockard's liquid which fixed the eggs and revealed the embryos). The percentages of Wi and Ei were computed at $i$ days and the survival rate estimated by $\mathrm{Si}=\frac{\mathrm{Ei}}{\mathrm{Ei}+\mathrm{Wi}_{\mathrm{i}}}$ p. 100. The techniques used for karyological examination of the blastulae were those previously described by Simon (1963). The slides were stained and covered according to Jaylet's method (1971).

\section{Results.}

1. Dose effect. - The sperm collected from 3 males was given 15-min doses of 9 to $250 \mathrm{krad}$. The eggs obtained after mixing three spawns were fertilized at the rate of $2 \mathrm{cc} / 1000$ eggs. We computed the white eggs at $D_{5}, D_{13}, D_{18}$ and $D_{20}$ and the live ones at $D_{27}$. The following results are shown in figures 1 and 2 .

- The lowest doses caused a complete embryonic loss reflected in the increase of the percentage of white eggs. The rate of clear eggs and eggs with an embryo increased with the dose.

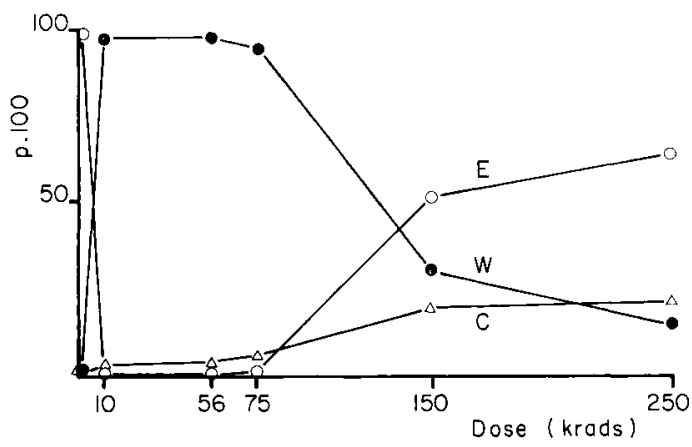

FIG. 1. - Dose effect. The frequencies of the three classes of eggs E : with an embryo ; $W$ : aborted ; $C$ : unfertilized) were computed at Day 27. 
- Survival rate variations in terms of incubation time (fig. 2) allowed us to distinguish two different batches : (i) those corresponding to the higher doses in which most of the embryos lived past $D_{27}$ but died before hatching (embryos with many morphological abnormalities : short body, small eyes, weak vascularization around the yolk), and (ii) those corresponding to the lower doses and generally aborting before $D_{13}$.

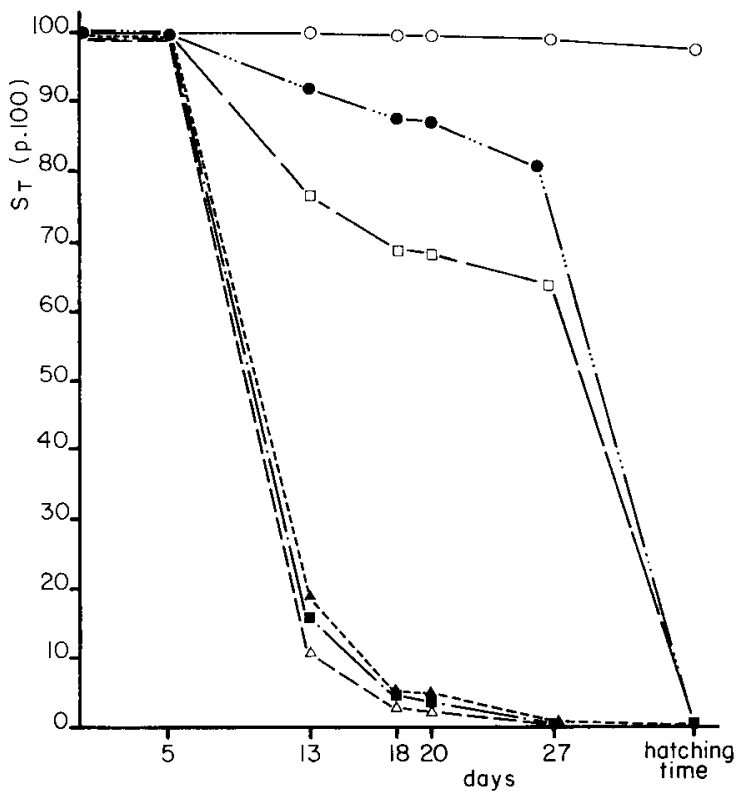

FIG. 2. - Survival rate variations ( $\mathrm{S}: \mathrm{E} / \mathrm{E}-\mathrm{W}$ ) in terms of the incubation time reveal two types of batches : low doses characterized by early abortion and high doses by abortion at hatching time.

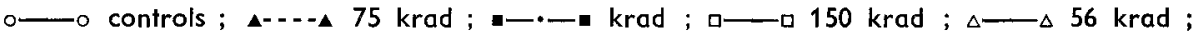
$\bullet-\cdots \longrightarrow 250 \mathrm{krad}$.

- All the histological slides (50) corresponding to the 150 -krad batch resembled those in fig. 3. The nuclei contained an haploid genetic set $(n=30)$.

2. Volume of sperm per egg. - We irradiated $(150 \mathrm{krad}$ for $15 \mathrm{~min}$ ) a mixture of sperm removed from 2 males and tested it with eggs collected from 10 females, then compared its effect with that of the non-irradiated sperm. The latter was equally effective at all dilutions, whereas the treated sperm lost 50 p. 100 of effectiveness when the volume was less than $0.5 \mu \mathrm{l} / \mathrm{egg}$ (dilutions of $0.5,1,2,3 \mu \mathrm{l} / \mathrm{egg}$ gave equivalent results). Volumes higher than $0.5 \mu \mathrm{l} / \mathrm{egg}$ were always used in the other experiments described in this paper.

3. Dose rate and time-course between spem collection and fertilization. - For the same total doses, we compared two durations (20 and $60 \mathrm{~min}$ ) and two fertilization delays ( $T=3$ and $5 \mathrm{hrs}$ ) in a three-factor factorial experiment. The analysis of 


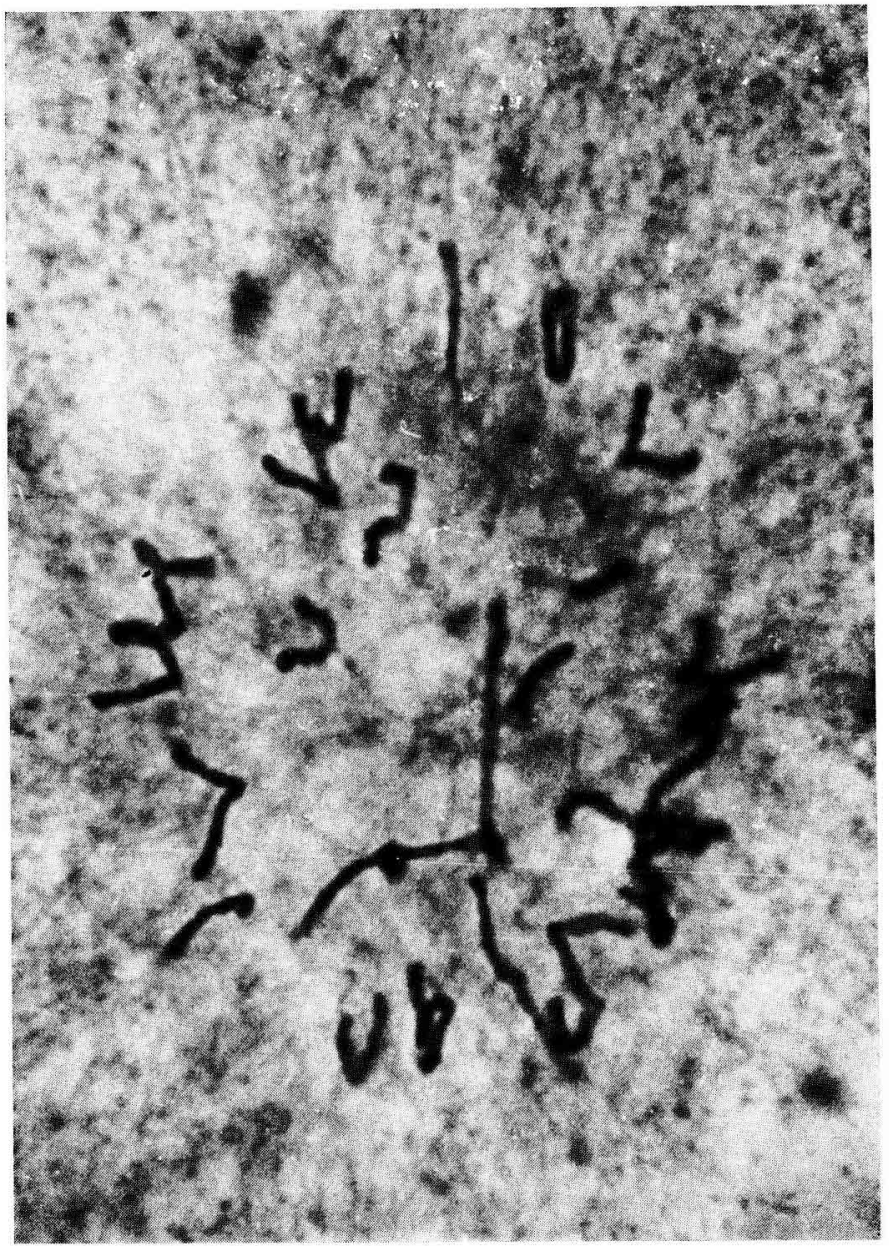

FIG. 3. - Haploid metaphase $(\mathrm{n}==30)$ corresponding to 150 -krad irradiation.

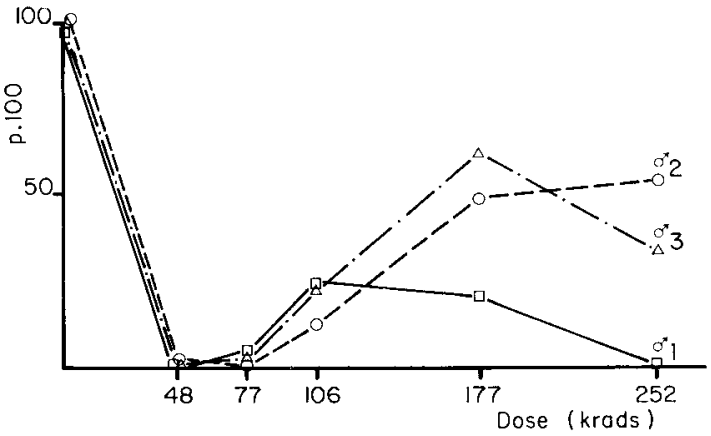

FIG. 4. - Dose effect varies widely among 3 males, making it difficult to determine the most efficient dose. 
variance, obtained from the results of computations at $D_{12}$ (tables $1 a, b$ ), did not reveal a significant effect for either parameter.

TABLE 1

Effect of dose rate variations and $T$

(time-course between sperm collection and fertilization)

1a) Results (p. 100 of eggs with an embryo)

\begin{tabular}{|c|c|c|c|c|c|c|c|c|c|}
\hline & \multirow{2}{*}{ Dose rate $(\mathrm{min})$} & \multicolumn{8}{|c|}{ Dose krad } \\
\hline & & 0 & 18 & 37 & 56 & 75 & 112 & 150 & 225 \\
\hline \multirow{2}{*}{$\mathrm{T}=3 \mathrm{~h}$} & 20 & $\begin{array}{l}71.65 \\
59.41\end{array}$ & $\begin{array}{l}0.00 \\
0.85\end{array}$ & $\begin{array}{l}0.00 \\
0.46\end{array}$ & $\begin{array}{l}2.82 \\
1.47\end{array}$ & $\begin{array}{l}18.32 \\
16.48\end{array}$ & $\begin{array}{l}22.60 \\
22.86\end{array}$ & $\begin{array}{l}32.37 \\
31.79\end{array}$ & $\begin{array}{r}13.59 \\
4.98\end{array}$ \\
\hline & 60 & $\begin{array}{l}71.65 \\
59.41\end{array}$ & $\begin{array}{l}0.00 \\
0.57\end{array}$ & $\begin{array}{l}0.00 \\
1.61\end{array}$ & $\begin{array}{l}2.22 \\
2.55\end{array}$ & $\begin{array}{r}15.57 \\
7.77\end{array}$ & $\begin{array}{l}38.29 \\
26.32\end{array}$ & $\begin{array}{l}36.28 \\
29.31\end{array}$ & $\begin{array}{l}3.79 \\
1.71\end{array}$ \\
\hline \multirow{2}{*}{$T=5 \mathrm{~h}$} & 20 & $\begin{array}{l}78.97 \\
80.79\end{array}$ & $\begin{array}{l}0.00 \\
0.00\end{array}$ & $\begin{array}{l}0.00 \\
0.53\end{array}$ & $\begin{array}{l}1.53 \\
3.94\end{array}$ & $\begin{array}{l}7.07 \\
7.89\end{array}$ & $\begin{array}{l}25.23 \\
23.56\end{array}$ & $\begin{array}{l}31.63 \\
38.07\end{array}$ & $\begin{array}{l}38.97 \\
12.08\end{array}$ \\
\hline & 60 & $\begin{array}{l}78.97 \\
80.79\end{array}$ & $\begin{array}{l}0.42 \\
0.45\end{array}$ & $\begin{array}{l}1.44 \\
1.99\end{array}$ & $\begin{array}{l}3.13 \\
2.04\end{array}$ & $\begin{array}{l}15.79 \\
16.52\end{array}$ & $\begin{array}{l}32.16 \\
29.20\end{array}$ & $\begin{array}{l}42.68 \\
41.09\end{array}$ & $\begin{array}{l}25.74 \\
41.09\end{array}$ \\
\hline
\end{tabular}

1b) Statistical analysis

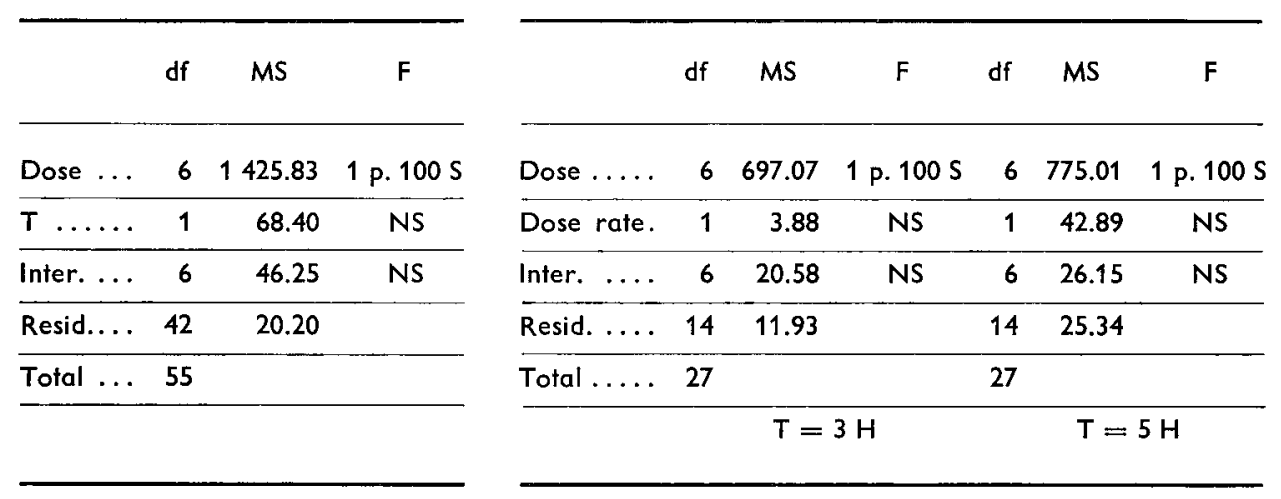

4. Choice of males and sperm mixfure. - The sperm of 3 males was compared after 5 different irradiation doses. The results at $D_{23}$ (fig. 4) showed wide variations among the males. Expecting to reduce this variability, we studied seven doses between 120 and 210 krads and compared the curve corresponding to a mixture of four sperm batches removed from 4 different males (fig. 5) with those of the individual results and their arithmetical mean. The embryonic development rate of males was found to vary again, and there was a favorable effect of sperm mixture, enhanced when the individual results were more heterogeneous. 


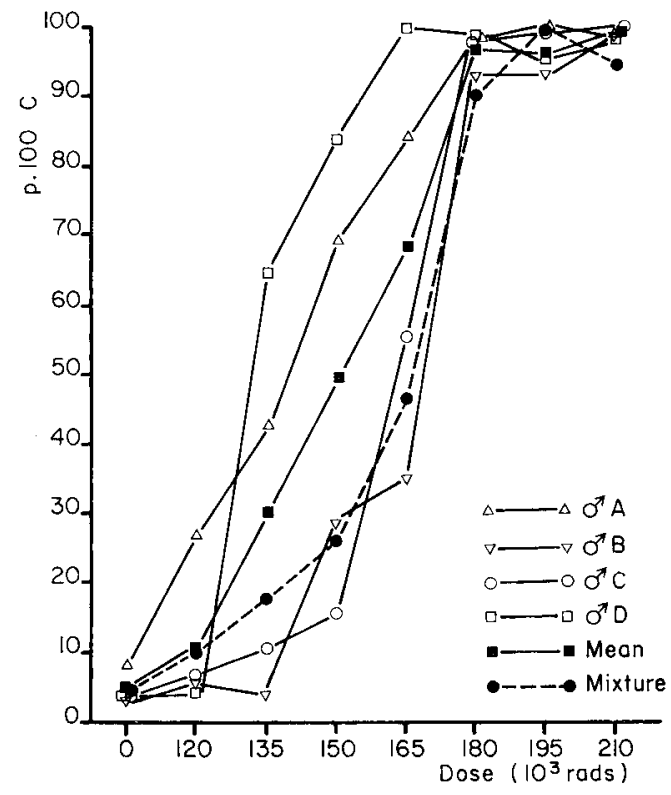

FIG. 5. - Effect of sperm mixture (different males) computed at Day 10

(C : unfertilized eggs).

Still expecting to reduce the variability, we analyzed a sperm mixture given three different doses (table 2). The results were slightly better than the arithmetical mean, but no significant different was found.

TABLE 2

Effect of mixing sperm given three different doses

\begin{tabular}{|c|c|c|c|c|}
\hline & $\begin{array}{c}\text { No. } \\
\text { of eggs }\end{array}$ & $\begin{array}{l}\text { P. } 100 \\
\text { of } E\end{array}$ & $\begin{array}{l}\text { P. } 100 \\
\text { of } W\end{array}$ & $\begin{array}{l}\text { P. } 100 \\
\text { of } C\end{array}$ \\
\hline $110 \mathrm{krad} . . . .$. & 270 & 42.2 & 23.3 & 34.5 \\
\hline $150 \mathrm{krad} . . . .$. & 263 & 23.2 & 26.7 & 60.1 \\
\hline $190 \mathrm{krad} . . . .$. & 314 & 28.9 & 16.8 & 54.3 \\
\hline 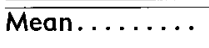 & 847 & 31.4 & 18.7 & 49.9 \\
\hline Mixture....... & 309 & 33.3 & 23.0 & 43.7 \\
\hline
\end{tabular}

\section{Discussion and conclusions.}

1. The number of live embryos in the different batches showed a typical Hertwig effect, i.e. the following variations in terms of the dose level : (i) a sharp decrease to zero for the low doses, then an increase to a maximum (at around $150 \mathrm{krad}$ ), (ii) an 
increment $\mathrm{n}$ the number of abortive eggs, followed by a decrease, the maximum corresponding to the first zero of the preceding curve. Abortion usually occurred before gastrulation, and the survivors observed later belonged either to the control or to the batches that were fertilized with sperm given more than $50 \mathrm{krad}$.

The maximum haploid activation rate was obtained by using higher doses than those previously announced in other papers (Vassileva-Dryanovska and Belcheva, 1965 ; Purdom, 1969). The use of an appropriate sperm diluent (extending the duration of sperm activity and considerably reducing the requisite number of spermatozoa for one egg) might play a role in these results.

2. Karyological examination of « high-dose » batches revealed the haploidy of the developing embryos, probably subsequent to gynogenesis. Edwards (1957) working on the mouse showed that the $X$-irradiated male pronucleus entered the eggs and was extruded during the first cleavages, whereas UV irradiation prevented its entering at all. In Pleurodeles waltlii after X-irradiation, Gaillard (1974) recognized a residue of replicated paternal chromatin in several larvae and advised the use of UV rays. We did not observe such a phenomenon, but our karyological methods did not permit any very definitive conclusions. However, and according to many authors, we speculated that the Hertwig effect was a consequence of differential viability between the eggs having received and replicated an irradiated male pronucleus (antegastrulation abortion) and those having developed without paternal genetic set at all (haploid).

3. Analysis of the variation factors showed that the dose rate and the time-course between sperm collection and fertilization did not influence the results, and that the wide differences among males could be reduced by mixing their sperm. Also, mixing several batches of sperm, which had received different doses, could increase the repeatability of the treatment. To summarize, it is now possible to use the $\gamma$-ray treatment, which is efficient enough, for further study of diploid restoration.

Reçu en septembre 1979.

Accepté en novembre 1979.

Acknowledgments. - We wish to thank M. Pinet, Centre d'Etudes Nucléaires, Saclay, for gamma irradiation facilities and Mrs Daifuku for her help in translating this manuscript.

Résumé. Au cours de ce travail, nous avons cherché à optimiser le traitement du sperme aux rayons $\gamma$ dans le but d'obtenir après insémination des taux élevés de développements gynogénétiques haploïdes. L'analyse de doses croissantes a montré un effet Hertwig typique dans tous les cas, mais nous avons enregistré pour la dose optimale d'importantes variations dues au mâle utilisé. Cette variabilité peut être réduite en utilisant un mélange de plusieurs fractions de sperme irradiées (provenant de mâles différents ou ayant reçu différentes doses efficaces).

\section{References}

BILLARD R., 1974. L'insémination artificielle de la Truite Salmo gairdneri Richardson. IV. Effet des ions $\mathrm{K}$ et $\mathrm{Na}$ sur la conservation de la fertilité des gamètes. Bull. fr. Pisc., 256, 88-100. 
EDWARDS R. G., 1957. The experimental induction of gynogenesis in the mouse. I. Irradiation of the sperm by $X$-rays. Proc. roy. Soc., 146, 469-487.

FANKHAUSER G., 1945. The effects of changes in chromosome number on amphibian development. Quant. Rev. Biol., 20, 20-78.

GAILLARD G., 1974. Contribution à l'étude de la tétraploïdie obtenue par choc thermique et de la gynogenèse chez l'Amphibien Pleurodeles Waltlii. Th. Doct., spécial. Biol. anim., Univ. Paul Sabatier, Toulouse.

GOLOVINSKAIA K. A., 1968. Genetics and selections of fish and artificial gynogenesis of the carp (Cyprinus carpio). FAO Fish. Rep. $\mathrm{n}^{\circ} 44$, Vol. 4, Proc. Wolrd Symp. on Warm Water Pond Fish Culture, Rome, 1966, 215-222.

HERTWIG O., 1911. Die Radiumkı ankheit tieriscker Keimzellen. Arch. mikr. Anat., 77, 1-97.

JAYLET A., 1971. Modification du caryotype par inversion péricentrique à l'état homozygote chez l'Amphibien urodèle Pleurodeles waltlii Michahelles. Chromosoma (Berl.), 35, 288-299.

LINCOLN R. F., AULSTAD D., GRAMMELTVEDT A, 1974. Attempted triploid induction in Atlantic salmon (Salmo salar) using cold shocks. Aquaculture, 4, 287-297.

NAGY A., RAJKI K., HORVATH L., CSANYI V., 1978. Investigation on carp, Cyprinus carpio L. gynogenesis. J. Fish Biol., 13, $215-224$.

PURDOM C. E., 1969. Radiation induced gynogenesis and androgenesis in fish. Heredity, 24, 431-444.

ROMASHOV D. D., NIKOLYUKIN N. I., BELYAEVA V. N., TIMOFEEVA N. A., 1963. Possibilities of producing diploid radiation-induced gynogenesis in sturgeons. Radiobiologiya, 3, 104-109 (transl. from Russ., Radiobiology, 3, 145-154).

ROSTAND J., 1934. Gynogenèse du crapaud par refroidissement de l'œuf. C. R. Soc. Biol., 115, 1680-1681.

SIMON R. C., 1963. Chromosome morphology and species evolution in the five North America species of Pacific salmon (Oncorhynchus). J. Morph., 112, 77-97.

STANLEY J. G., 1976. Female homogamety in grass carp (Cfenopharyngodon idella) determined by gynogenesis. J. Fish. Res. Bd. Can., 33, 1372-1374.

VASSILEVA-DRYANOVSKA O., BELCHEVA R., 1965. Radiation gynogenesis in Salmo irideus Gibb. C. R. Acad. bulg. Sci., 18, 359-362.

VERNIER J. M., 1969. Table chronologique du développement embryonnaire de la truite Arc-enciel. Ann. Embryol. Morph., 2, 495-520. 